\title{
Door Opening with Fingerprint
}

\author{
J. Carmona, E. Mendoza, M. Sanchez \\ Professor \\ Department of Industrial Maintenance Engineering \\ Universidad Tecnologica De Tlaxcala \\ Tlaxcala, Mexico
}

\begin{abstract}
For the next project they were used the following components: a biometric sensor, push buttons, 16x2 LCD screen, electric plate, an Arduino, relay, RTC (real time clock), internal storage memory.

With the components, a biometric security system was designed to open the door itself that uses the fingerprint, and data storage in SD (secure Digital), using the CC + programming language for simple commands as a new fingerprint registration, deletion ID (identification), and also data storage in an SD (secure Digital) which will allow us to know the hours of staff entry through the RTCsensor (real time clock), days for week and most importantly security in the laboratory in which it was implemented. This in order to facilitate the collection of information in a simpler way, using a database that is stored in an internal storage memory using a blog of notes for registration, and thus facilitate the control of logbooks, and in case if necessary, you can evaluate the conditions of the area indicating when it was the last access to the preventive maintenance laboratory, where it was implemented.
\end{abstract}

The results obtained were the rapid accessibility to said laboratory with the fingerprint, as well as the storage of data, which are visible in the document protected in the internal memory

\section{INTRODUCTION}

As time passes and the world advances along with the constant increase in crime and insecurity that is lived day by day at the national level, it is that security and the mechanisms to feel and be safe have become a fundamental part of the life of a human being, as well as the integral development of the home, business, or company to protect them. [1].

At the time this occurs, this type of security is designed, built and installed in Alan's laboratory. In this way there will be greater control in the access of the laboratory, this will cause that by inertia there is more confidence in the student when performing activities within the laboratory. [2]

It is known that today it is too easy to manipulate a sheet or a bolt, here is the foundation and the importance of developing the project, the implementation of a fingerprint biometric sensor which will allow strict control of who can and will not be able to enter Similarly, a record of time, date of entry and exit of each individual who has authorization to enter the aforementioned laboratory is kept. [2]

With this project, it is possible to implement greater safety in the laboratory since it will prevent other students from different careers and unauthorized personnel from entering without permission, thus avoiding losses in components and equipment that are inside the laboratory.

\author{
E. Aguila, L. A. Barrientos, G. Ceron, \\ F. Galvez, G. Martinez \\ Students \\ Department of industrial maintenance Engineering \\ Universidad tecnologica de Tlaxcala, Mexico
}

\section{ASSEMBLY BIOMETRIC SYSTEM}

Biometric access control is an identification system based on the user's biological qualities, within this system, we can differentiate between different types of recognition which were already mentioned and in this case the system will be fingerprint.

Biometric access control has the following advantages:

Low maintenance cost. Once the installation is done, this type of access control has a much lower maintenance cost compared to other systems.

Provides a high dose of safety. This type of control is the safest system, the fingerprint is a unique and unrepeatable feature in each person.

Does not require additional door opening devices. By using a unique feature of the person, which in this case is fingerprint.

There is no loss of keys.

Can be placed in tight spaces.

Protect users from possible phishing.

Loss of access cards and passwords is avoided.

They are fast systems that allow more fluid work.

No need to remember.

Easy to use.

Accessible for everyone.

Allows presence control.

The process is fast.

Greater access control. [3]

\section{BIOMETRICS CLASSIFICATION}

Static: this is in charge of the physical and / or biological characteristics that an object or individual has to be identified.

Dynamic: This is responsible for studying the behavior of the individual to determine the unique behaviors that differentiate it from other individuals.. [4]

\section{TYPES OF FINGERPRINT}

Natural fingerprint: This is the one found on the fingertip, formed by the papillary ridges naturally. [1]

Artificial fingerprint: It the drawing that appears as a result when printing in a certain way with the help of an ink the natural on a surface. [2]

Latent fingerprint: It a fingerprint left by any natural fingerprint when touching an object or surface. This 
fingerprint is marked, but not visible. To obtain the visibility of the footprint, a suitable reagent must be applied.

The following components were described for the development of the project:

\section{ARDUINO}

Arduino is a programming system for $\mathrm{C} / \mathrm{C}++$ languages with electronic platforms that use microcontrollers to form embedded systems specialized in process automation, so it has a great application within engineering. This type of platform has become popular due to the economic scope and attractiveness to develop automation applications for any physical process. [5]

\section{BIOMETRIC SENSOR}

The biometric sensor is a mechanical or electronic system used to record and capture biometric samples. Most of these sensors are used as representatives of our physical being in the digital realm. [5]

\section{SD MODULE (SECURE DIGITAL)}

This module allows connections to be made quickly and easily as a memory card can be connected to a microcontroller, so that large amounts of data can be stored using a microcontroller as a control device. This is ideal for projects such as MP3 players, data loggers, etc. [6]

\section{LCD SCREEN (LIQUID CRYSTAL DISPLAY)}

LCD screen (Liquid Crystal Display): 16 characters x 2 lines, $5 \times 8$ points characters and character size: $5.23 \times 3 \mathrm{~mm}$.

This can display letters, numbers, special characters, and up to 8 characters created by the user.

Blue LED backlight [7]

\section{RTC (REAL TIME CLOCK)}

A Real-Time Clock (RTC) is the clock of an computer, included in an integrated circuit, that keeps the current time units. [6]

\section{Relay}

Plate relays support AC loads up to 250VAC / 10A and DC loads up to 30VDC / 10A. In addition to having screw terminals for easy connection and LED activity ON / OFF for each Relay. [7]

\section{Assembly}

Step 1: As a first base we carry out a program that allows us to store, delete and erase fingerprints in the Arduino version 1.8.9 program. see figure 1,2 .

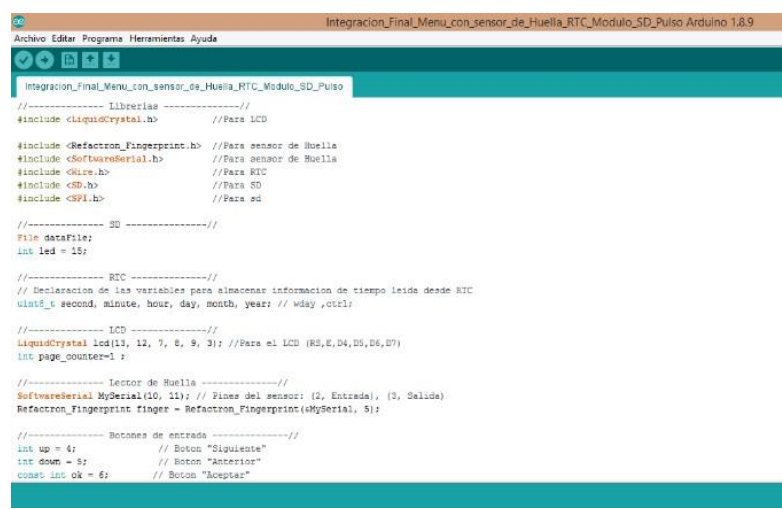

Figure 1 code

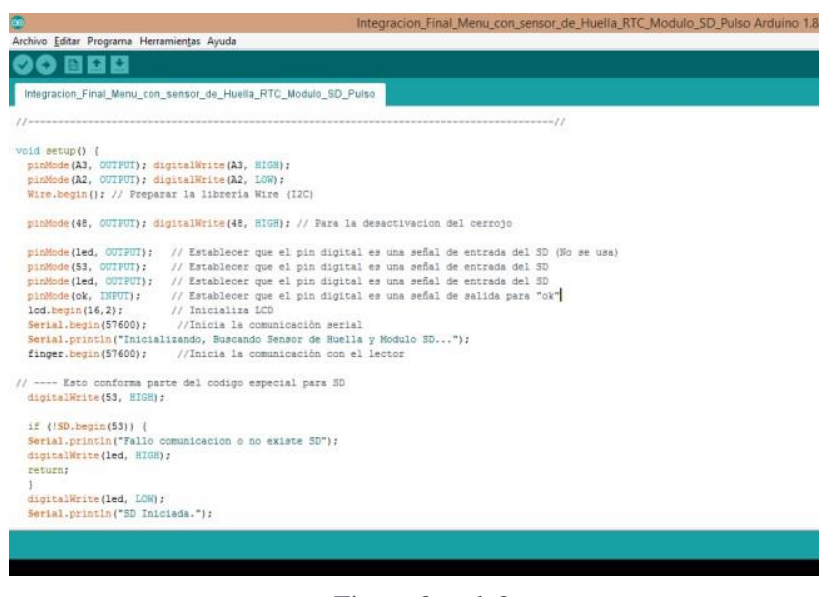

Figure 2 code 2

Step 2: Connect the Arduino and the sensor. Figure 3

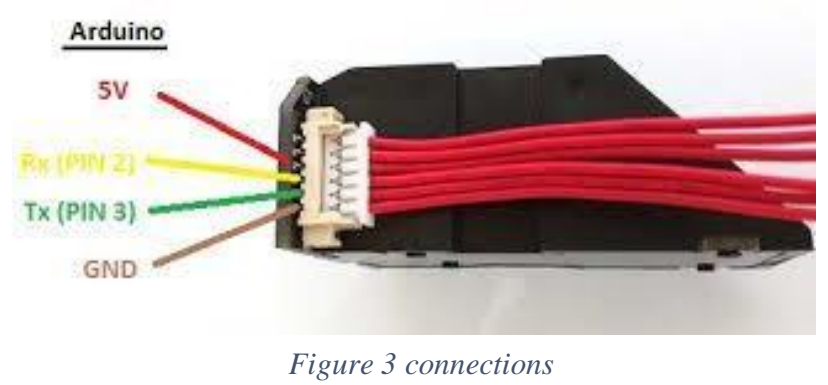

Step 3. Open the Arduino Series Monitor to start recording the tracks and follow the instructions: figure 4, 5 .

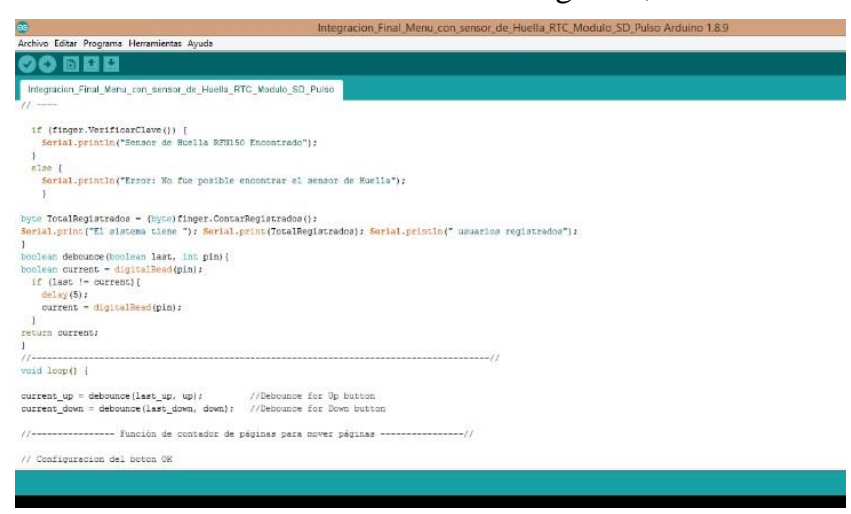

Figure 4 finger record 


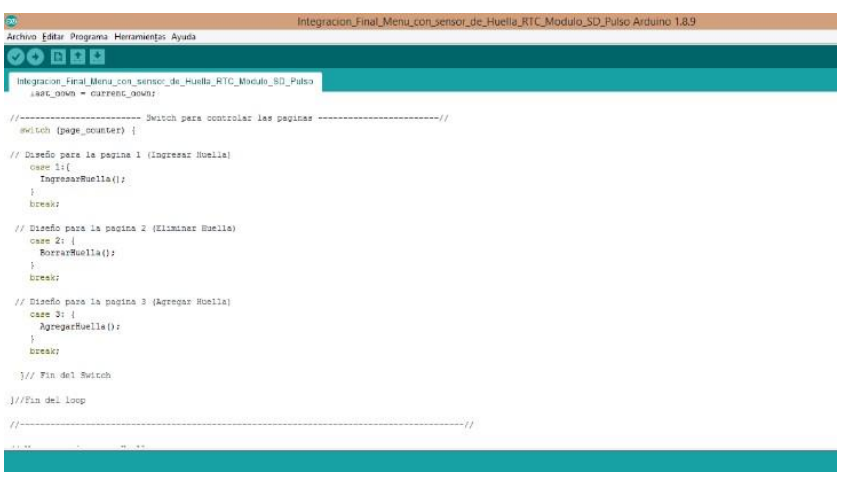

Figure 5 record 1.1

Step 4: Use the pins (A5 and A6) to connect SD module connection (secure Digital). Figure 6.

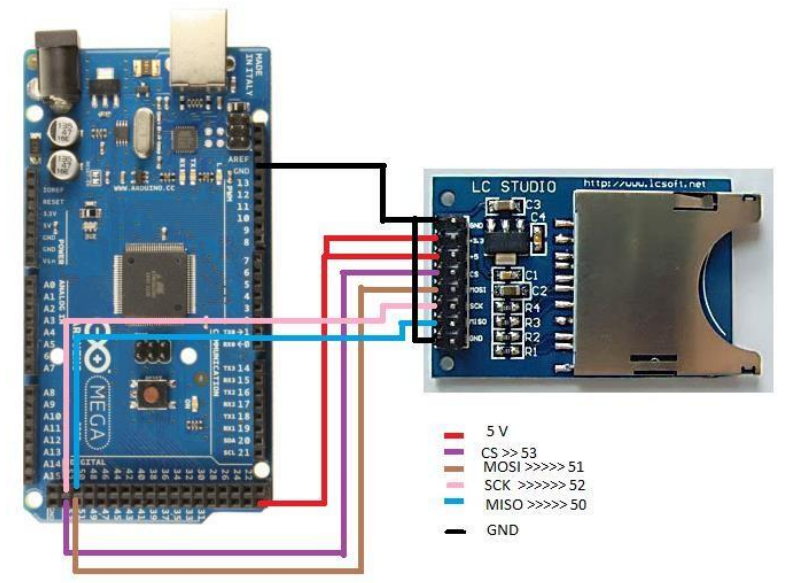

Figure 6 connection, source: google

Step 5: Connect LCD Screen connection (Liquid Crystal Display)

As you can see the screen has 16 pins which will be connected to one of the terminals $(3,4,5,6,7,8,11,12,13,14$, voltage 5 volts and GND ground) in the Arduino mega. Figure 7, 8 .

\section{Figure 7 Arduino mega}

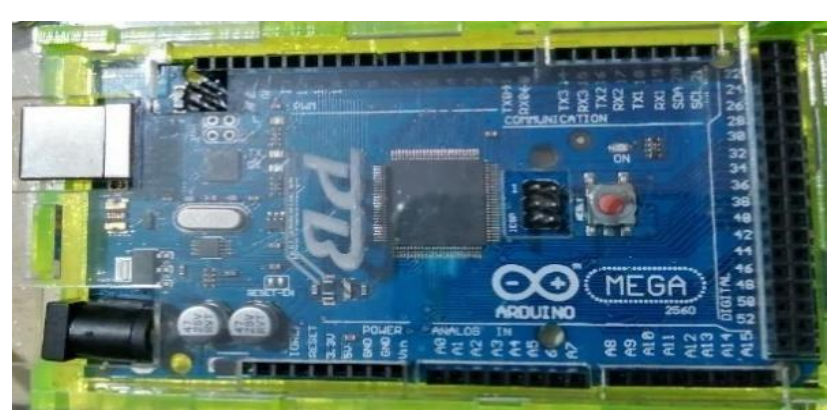

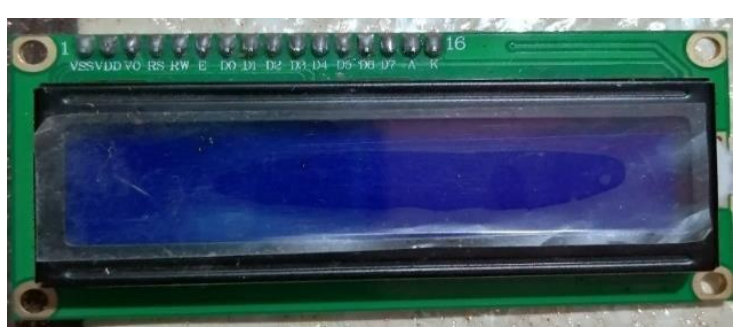

Figure 8 screen

Step 6: Sheet and relay connection to connect the sheet to the relay we use a direct current and a ground (GND). Figure 9.

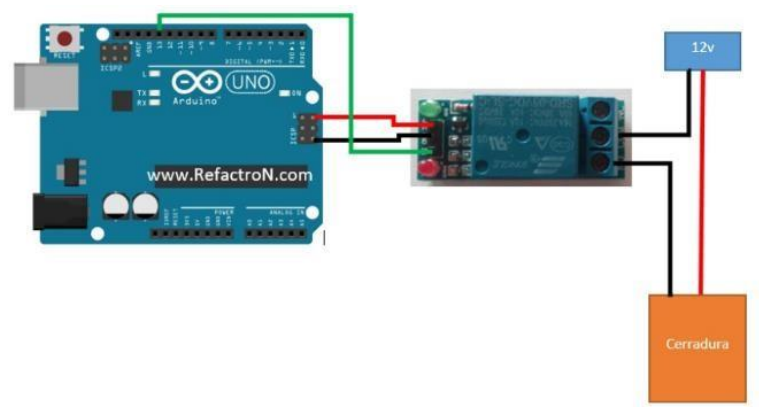

Figure 9 relay, source: google

Step 8: To connect RTC (real time clock). we use the entries (A1, A3) and a 5 volts current of Arduino mega. Figure 10.

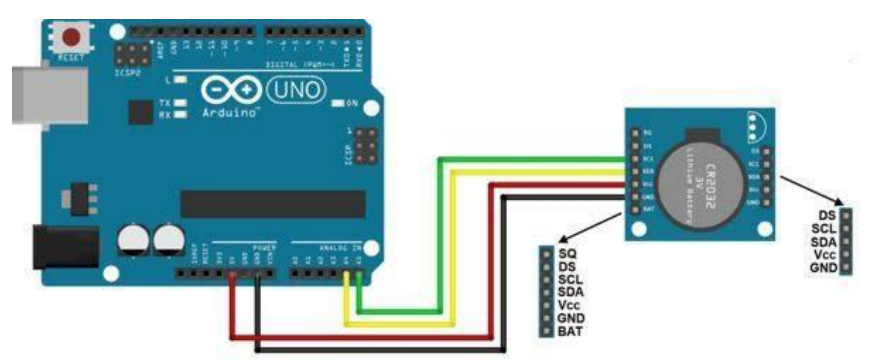

Figure 10 RTC, source: google 
RESULTS OBTAINED

Table 1 Tests

\begin{tabular}{|l|l|l|}
\hline SITUATION & YES & NO \\
\hline Oil & $\mathrm{X}$ & \\
\hline ink & $\mathrm{x}$ & \\
\hline Scratch & & $\mathrm{X}$ \\
\hline Cold & $\mathrm{X}$ & \\
\hline Hot & $\mathrm{X}$ & \\
\hline Grease & & $\mathrm{x}$ \\
\hline Earth & & $\mathrm{X}$ \\
\hline humidity & $\mathrm{x}$ & \\
\hline
\end{tabular}

According to the experiment performed with different physical factors as shown in table 1 . The application of the biometric sensor was obtained in $70 \%$ effectiveness in different circumstances in which the fingerprint is found. See table 1.

\section{CONCLUSION}

With the development of this project, we were able to conclude that the university's student community, regardless of gender, wants to feel safe with their personal objects, within the facilities. And it is necessary that the institution implements an access control system that serves as a collaboration to managers and managers in areas, in order to have control of the people who enter and leave the university.

An access control system turns out to be a great tool since it allows you to control access, limiting the entrance to people from outside.

At present, taking care of the assets is important due to the increase in robberies, so new technologies are implemented to reduce risk.

\section{AUTHORS AND AFFILIATIONS}

Jonny Carmona Reyes graduated from the Technological Institute of Apizaco in 2010 with a bachelor's degree in Electronic Engineering, specialty in automation and

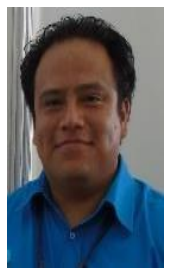
instrumentation. $\mathrm{He}$ worked as an electronic engineer in MIF company, developing electronic projects for the steel industry from 2010 to 2015. Since to 2013, he has been working as a teacher in the Technological University of Tlaxcala in the industrial maintenance career.

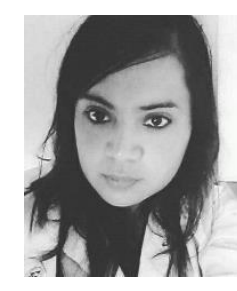

Gabriela Martinez Vazquez graduated from the Technological University of Tlaxcala in 2018 with a degree of Higher University Technician in Maintenance Industrial Area He completed his stay process at Empacadora Silva SA CV and is currently studying Industrial Engineering Engineering at the Technological University of Tlaxcala.

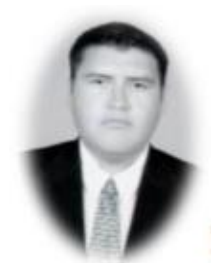

Moisés Sánchez Moredia earned a Bachelor of Arts in Applied Modern Languages, specialized in English as a second language teaching by Universidad Autónoma de Tlaxcala. He holds a Master's Degree in School Administration and Management by Universidad Internacional de la Rioja

(UNIR). From 2016 to 2018, He was the coordinator of the English area in Universidad Tecnologica de Tlaxcala where he currently teaches English in Industrial Maintenance Engineering.

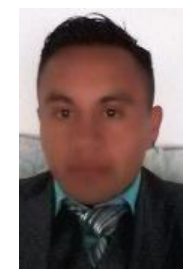

German Ceron Guevara graduated from the Technological University of Tlaxcala in 2017 with a degree of Higher University Technician in Maintenance Industrial Area Hecompleted his stay process at T-Bell Telecom, worked for 6 months at Interlift Elevators and is currently studying Industrial Engineering Engineering at the Technological University of Tlaxcala.

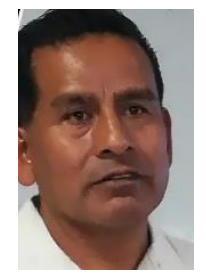

Ernesto Mendoza Vazquez teacher researcher of time complete in the Technological University of Tlaxcala as well as academic corps in industry maintenance

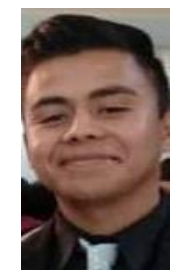

Eric Aguila Juarez graduated from Tlaxcala Technological University in 2018 with a degree of University Superior Technician in Maintenance Industrial Area Currently studying the degree of Industrial Maintenance Engineering at the Technological University of Tlaxcala.

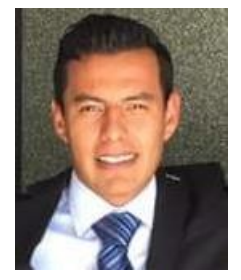

Francisco Galvez Morales graduated from the Technological University of Tlaxcala in 2018 with a degree of Higher University Technician in Maintenance Industrial Area He completed his stay process at Empacadora Silva SA CV and worked for 6 months at Acaprec is currently studying Industrial

Engineering Engineering at the Technological University of Tlaxcala. 
Luis Alberto Barrientos Fernandez graduated from Tlaxcala Technological University in 2018 with a degree of University Superior Technician in Maintenance Industrial Area Currently studying the degree of Industrial Maintenance Engineering at the Technological University of Tlaxcala

\section{REFERENCES}

[1] D. Omar, «Clasificacion de impresiones dactilares,» 2009.

[2] V. C.C., «Biometría,» Barcelona, El libro catedra, 2007.

[3] M.Santos, «Sensores dehuellas dactilares: como funcionan y porqueno son tan seguros,» hardzone, 2018.

[4] B. B. A. J, «proceso integral de la huella dactilar,» Ciudad de Mexico, Smarhwords, 2018.

[5] F.REYESCORTÉSyJ.CIDMONJARAZ, «ARDUINO,» Alfaomega, 2015, p.468.

[6] F. Reyes Cortés y J. Cid Monjaraz, «Aplicaciones en robótica,mecatrónica e ingeníerias,» Monterrey, Marcombo, 2015.

[7] D. Ibrahim, «SDproyectosdetarjetas,»New York, Elsevier, 2005.

[8] C. Millahual, «Arduino para principiantes,» Buenos Aires, Loreta Blanco, 2017. 